\title{
Differences in cause of death of Washington State veterans who did and did not use Department of Veterans Affairs healthcare services
}

\author{
Charles Maynard, PhD; ${ }^{*}$ Edward J. Boyko, MD, MPH \\ Department of Veterans Affairs Epidemiologic Research and Information Center, Seattle, WA
}

\begin{abstract}
Relatively little is known about the cause of death in the veteran population, although more is known about the cause of death in Vietnam veterans or veterans receiving mental health services. This article compares characteristics and causes of death in Washington State veterans who did and did not use Department of Veterans Affairs (VA) healthcare services in the 5 years prior to death. This study included 62,080 veterans who died between 1998 and 2002, of whom 21\% were users of VA healthcare services. The veterans who used VA healthcare services were younger, more often men, less educated, more often divorced, and more often smokers than the veterans who did not use VA healthcare services. Both female and male veterans who used VA healthcare services were more likely to die from drugand/or alcohol-related causes. These findings suggest that the VA patient population is socially disadvantaged and more severely affected by substance-use disorders compared with veterans who do not use VA healthcare services.
\end{abstract}

Key words: death records, Department of Veterans Affairs, education, healthcare, mortality, rehabilitation, smoking, substance-use disorders, veterans, Washington State.

\section{INTRODUCTION}

Relatively little is known about the cause of death in the general veteran population, although more is known about the cause of death in Vietnam and Persian Gulf war veterans [1-3]. Veterans who received specialty mental health services died younger and were more likely to die from infectious diseases, accidents, or suicide than their counterparts who received general medical care only [4]. These findings are consistent with results from the civilian population [5].

Strong evidence exists that veterans who use Department of Veterans Affairs (VA) healthcare services are sicker than veterans who do not [6]. Whether age and cause of death differ among veterans who do and do not use VA healthcare services is unknown. We hope that this article will provide new information about cause of death in a large veteran population. Our first objective was to identify veterans who died in Washington State between 1998 and 2002 and determine whether they used VA healthcare services. Our second objective was to compare characteristics and causes of death according to VA healthcare use in the 5 years prior to death. We were particularly interested in whether the proportion of alcohol- and/or drug-induced deaths differed between users and nonusers of VA healthcare services.

\footnotetext{
Abbreviations: $\mathrm{CI}=$ confidence interval, $\mathrm{ICD}=$ International Classification of Diseases, OR = odds ratio, VA $=$ Department of Veterans Affairs, VAMC = VA medical center.

*Address all correspondence to Charles Maynard, PhD; Department of Veterans Affairs Epidemiologic Research and Information Center (152), 1100 Olive Way, Suite 1400, Seattle, WA 98101; 206-277-6496; fax: 206-764-2935. Email: cmaynard@u.washington.edu

DOI: 10.1682/JRRD.2006.01.0004
} 


\section{METHODS}

\section{Population}

We identified deceased veterans through Washington State death certificates, which include a question as to whether the decedent was ever in the Armed Forces of the United States. In this article, we include 62,080 Washington State veterans who died between 1998 and 2002. These veterans were identified from electronic death certificates provided by the Washington State Department of Health. An additional 1,462 veterans with missing or invalid Social Security numbers were not included because we needed the Social Security number to link to VA healthcare use files to identify users of VA healthcare services.

\section{Study Variables}

In addition to date of death and veteran status, we obtained from the death certificate each veteran's age, sex, race, education, marital status, and smoker status during the 15 years before death. The distances between each veteran's residence and the closest VA medical center (VAMC) and outpatient clinic were obtained from VA data sources. The underlying cause of death was also collected and reported using International Classification of Diseases (ICD)-9 codes for veteran deaths in 1998 and ICD-10 codes for deaths in 1999 to 2002. The ICD-9 and ICD-10 codes that we used to define the leading causes of death and alcohol- and/or drug-induced causes are shown in Appendix 1 and Appendix 2, respectively (available online only at http://www.rehab.research.va.gov/).

We obtained information concerning use of VA healthcare services 5 years prior to death by linking the Social Security number recorded on the death certificate with a similar number contained in the VA Austin Automation Center files. A scrambled identifier, which was obtained from the linkage, was then used to extract healthcare use information from the relevant Austin Automation Center files. Types of healthcare use included (1) outpatient, (2) acute hospital, (3) extended or nursing home, (4) observation, and (5) authorized nonVA acute hospital.

\section{Statistical Methods}

Analyses were performed separately for female and male veterans. To compare baseline characteristics of users and nonusers of VA healthcare services, we used the chi-square statistic for categorical variables and the two sample $t$-test for continuous variables. To examine the association between alcohol- and/or drug-induced deaths and use of VA healthcare services, we used the chi-square statistic. We also used logistic regression to determine the association between these two factors after adjusting for demographic and smoking variables.

\section{RESULTS}

Overall, 2,618 female veterans (4\% of sample) and 59,462 male veterans were studied; 12 percent of the females and 21 percent of the males used VA healthcare services in the 5 years prior to death. Of the 309 female veterans who used VA healthcare services, 99 percent had used outpatient services, 55 percent had been hospitalized in VAMCs, and 26 percent had extended care. Only two female veterans had been in observation beds and 9 percent had been hospitalized in non-VA facilities. A total of 12,730 male veterans used VA healthcare services and 99 percent received outpatient care. Approximately 52 percent of these males had been hospitalized in VAMCs, 21 percent had extended care, 2 percent had occupied observation beds, and 6 percent had been hospitalized in non-VA facilities.

Female veterans who used VA healthcare services were 4 years younger, more often divorced, and more often smokers than their counterparts who did not use VA healthcare services (Table 1). These differences were also true for the male veterans, as seen in Table 2 . In addition, male veterans who used VA healthcare services were more often nonwhite, less educated, and living closer to VA healthcare facilities than male veterans who did not use VA healthcare services.

For the relatively few female veterans who used VA healthcare services, malignant neoplasms were more often the underlying cause of death and cerebrovascular diseases were less often the cause of death (Table 3). Strikingly, alcohol- and/or drug-induced deaths were three times more common in female users of VA healthcare services (odds ratio [OR] $=3.10,95 \%$ confidence interval $[\mathrm{CI}]=1.71-5.60$ ). One must recognize, however, that only 56 females had alcohol- and/or drug-induced deaths. Of these, 29 percent used VA healthcare services in comparison with only 11 percent of the females who did not die of alcohol- and/or drug-related causes. The females with alcohol- and/or drug-induced deaths were 24 years younger (51 vs 75 years), more often single or 
Table 1.

Characteristics of deceased female veterans in Washington State who did $(n=309)$ and did not use $(n=2,309)$ Department of Veterans Affairs (VA) healthcare services.

\begin{tabular}{|c|c|c|c|}
\hline \multirow{2}{*}{ Characteristic } & \multicolumn{2}{|c|}{ Used VA Healthcare } & \multirow{2}{*}{$p$-Value } \\
\hline & Yes (\%) & No (\%) & \\
\hline Age (yr) & & & $<0.001$ \\
\hline 18-29 & 0 & $<1$ & \\
\hline $30-39$ & 3 & 2 & \\
\hline $40-49$ & 10 & 4 & \\
\hline $50-59$ & 11 & 6 & \\
\hline $60-69$ & 13 & 10 & \\
\hline $70-79$ & 32 & 33 & \\
\hline 80-89 & 25 & 33 & \\
\hline$\geq 90$ & 6 & 11 & \\
\hline Mean \pm Standard Deviation & $71 \pm 15$ & $75 \pm 14$ & $<0.001$ \\
\hline Race/Ethnicity & & & 0.41 \\
\hline White & 94 & 95 & \\
\hline African American & 4 & 2 & \\
\hline Native American & 1 & 1 & \\
\hline Asian & 1 & 1 & \\
\hline Hispanic & $<1$ & $<1$ & \\
\hline Education & & & 0.31 \\
\hline$\leq 8$ th Grade & 2 & 4 & \\
\hline Some High School & 3 & 4 & \\
\hline High School Graduate & 36 & 37 & \\
\hline Some College & 33 & 29 & \\
\hline College Graduate & 16 & 16 & \\
\hline Postgraduate Work & 9 & 10 & \\
\hline Marital Status & & & $<0.001$ \\
\hline Single & 13 & 10 & \\
\hline Married & 24 & 29 & \\
\hline Divorced & 31 & 17 & \\
\hline Widowed & 32 & 45 & \\
\hline Unknown & $<1$ & 0 & \\
\hline Closest VA Outpatient Clinic (mi) & & & 0.16 \\
\hline$\leq 10$ & 62 & 59 & \\
\hline $10-20$ & 20 & 18 & \\
\hline$>20$ & 18 & 22 & \\
\hline Closest VA Medical Center (mi) & & & 0.06 \\
\hline$\leq 20$ & 70 & 62 & \\
\hline $20-50$ & 14 & 18 & \\
\hline $50-100$ & 14 & 18 & \\
\hline$>100$ & 2 & 2 & \\
\hline Smoked in Past 15 Yr & 42 & 34 & 0.001 \\
\hline
\end{tabular}

divorced (65\% vs $28 \%$ ), and more often smokers (66\% vs $34 \%)$ than their counterparts who died from other causes.

For male veterans, the leading cause of death was similar for users and nonusers of VA healthcare services (Table 4). A total of 1,448 males had alcohol- and/or drug-induced deaths, the likelihood of which was higher
Table 2.

Characteristics of deceased male veterans in Washington State who did $(n=12,730)$ and did not use $(n=46,732)$ Department of Veterans Affairs (VA) healthcare services.

\begin{tabular}{|c|c|c|c|}
\hline \multirow{2}{*}{ Characteristic } & \multicolumn{2}{|c|}{ Used VA Healthcare } & \multirow{2}{*}{$p$-Value } \\
\hline & Yes $(\%)$ & No (\%) & \\
\hline Age (yr) & & & $<0.001$ \\
\hline 18-29 & $<1$ & $<1$ & \\
\hline $30-39$ & 1 & 1 & \\
\hline $40-49$ & 5 & 3 & \\
\hline $50-59$ & 13 & 8 & \\
\hline $60-69$ & 19 & 18 & \\
\hline $70-79$ & 36 & 37 & \\
\hline $80-89$ & 23 & 29 & \\
\hline$\geq 90$ & 2 & 4 & \\
\hline Mean \pm Standard Deviation & $71 \pm 12$ & $73 \pm 11$ & $<0.001$ \\
\hline Race/Ethnicity & & & $<0.001$ \\
\hline White & 91 & 96 & \\
\hline African American & 5 & 2 & \\
\hline Native American & 1 & 1 & \\
\hline Asian & 1 & 1 & \\
\hline Hispanic & 1 & $<1$ & \\
\hline Education & & & $<0.001$ \\
\hline$\leq 8$ th Grade & 12 & 9 & \\
\hline Some High School & 11 & 10 & \\
\hline High School Graduate & 41 & 40 & \\
\hline Some College & 21 & 20 & \\
\hline College Graduate & 9 & 12 & \\
\hline Postgraduate Work & 6 & 9 & \\
\hline Marital Status & & & $<0.001$ \\
\hline Single & 8 & 5 & \\
\hline Married & 51 & 63 & \\
\hline Divorced & 25 & 13 & \\
\hline Widowed & 16 & 19 & \\
\hline Unknown & $<1$ & $<1$ & \\
\hline Closest VA Outpatient Clinic (mi) & & & $<0.001$ \\
\hline$\leq 10$ & 60 & 55 & \\
\hline $10-20$ & 17 & 19 & \\
\hline$>20$ & 23 & 26 & \\
\hline Closest VA Medical Center (mi) & & & $<0.001$ \\
\hline$\leq 20$ & 61 & 58 & \\
\hline $20-50$ & 18 & 20 & \\
\hline $50-100$ & 18 & 20 & \\
\hline$>100$ & 3 & 2 & \\
\hline Smoked in Past 15 Yr & 47 & 37 & 0.001 \\
\hline
\end{tabular}

in those who used VA healthcare services ( $\mathrm{OR}=2.17$, $95 \%$ CI $=1.95-2.42$ ). Of the males with alcohol- and/or drug-induced deaths, 37 percent used VA healthcare services, as opposed to only 21 percent who did not have alcohol- and/or drug-induced deaths. These males with alcohol- and/or drug-induced deaths were younger (58 vs 
Table 3.

Leading causes of death among female veterans in Washington State who did $(n=309)$ and did not use $(n=2,309)$ Department of Veterans Affairs (VA) healthcare services.

\begin{tabular}{lcc}
\hline \multirow{2}{*}{\multicolumn{1}{c}{ Cause of Death }} & \multicolumn{2}{c}{ Used VA Healthcare } \\
\cline { 2 - 3 } & Yes (\%) & No (\%) \\
\hline Diseases of Heart & 20.4 & 21.9 \\
Malignant Neoplasms & 31.7 & 26.3 \\
Cerebrovascular Diseases & 6.8 & 9.4 \\
Chronic Lower Respiratory Diseases & 4.2 & 7.9 \\
Accidents (unintentional injuries) & 3.6 & 3.3 \\
Diabetes Mellitus & 2.3 & 2.0 \\
Influenza and Pneumonia & 0.6 & 2.4 \\
Nephritis, Nephritic Syndrome, and Nephrosis & 0.0 & 0.7 \\
Intentional Self-Harm (suicide) & 1.6 & 0.9 \\
Septicemia & 0.3 & 0.8 \\
Chronic Liver Disease and Cirrhosis & 0.6 & 0.7 \\
Assault (homicide) & 0.0 & 0.4 \\
Human Immunodeficiency Virus & 0.0 & 0.0 \\
Other & 27.9 & 23.3 \\
Alcohol- and/or Drug-Induced & 5.2 & 1.7 \\
\hline \hline
\end{tabular}

73 years), more often single or divorced (54\% vs $20 \%$ ), and more often smokers (69\% vs 39\%) than the males who died from other causes.

Adjusting for differences between users and nonusers of VA healthcare services did not appreciably change the observed association between cause of death and use of VA healthcare services for either females or males. For the 2,585 females with complete information, we adjusted for age, marital status, and smoking and found that the odds of an alcohol- and/or drug-induced death were more than two times higher in female veterans who used VA healthcare services (OR $=2.13,95 \% \mathrm{CI}=1.11-4.07)$. For the 58,431 males with complete information, we adjusted for age, marital status, smoking, education, and race/ethnicity and found that the odds of an alcohol- and/or drug-induced death were also higher among the users of VA healthcare services $(\mathrm{OR}=1.53,95 \% \mathrm{CI}=1.36-1.72)$.

\section{DISCUSSION}

In this study of deceased Washington State veterans, only about 20 percent used VA healthcare services during the 5 years prior to death. This finding is very similar to results from the 2001 National Survey of Veterans in which 23 percent of veterans used VA healthcare services (http://www1.va.gov/vetdata/). The 62,080 veterans that we studied represented 28 percent of the 221,976

\section{Table 4.}

Leading causes of death among male veterans in Washington State who did $(n=12,730)$ and did not use $(n=46,732)$ Department of Veterans Affairs (VA) healthcare services.

\begin{tabular}{lcc}
\hline \multirow{2}{*}{ Cause of Death } & \multicolumn{2}{c}{ Used VA Healthcare } \\
\cline { 2 - 3 } & Yes (\%) & No (\%) \\
\hline Diseases of Heart & 25.7 & 27.3 \\
Malignant Neoplasms & 27.3 & 29.8 \\
Cerebrovascular Diseases & 5.6 & 6.6 \\
Chronic Lower Respiratory Diseases & 7.9 & 6.4 \\
Accidents (unintentional injuries) & 3.5 & 3.1 \\
Diabetes Mellitus & 3.3 & 2.3 \\
Influenza and Pneumonia & 2.3 & 2.0 \\
Nephritis, Nephritic Syndrome, and Nephrosis & 0.8 & 0.6 \\
Intentional Self-Harm (suicide) & 1.8 & 1.9 \\
Septicemia & 0.7 & 0.6 \\
Chronic Liver Disease and Cirrhosis & 2.3 & 1.2 \\
Assault (homicide) & 0.2 & 0.2 \\
Human Immunodeficiency Virus & 0.3 & 0.2 \\
Other & 18.3 & 17.8 \\
Alcohol- and/or Drug-Induced & 4.2 & 2.0 \\
\hline \hline
\end{tabular}

persons who were over 18 and listed in Washington State death records for 1998 through 2002. Female veterans, who were 4 percent of all deceased veterans in this study, were less likely to use VA healthcare services and represented only 2 percent of VA healthcare recipients. This finding was expected given that not all VAMCs offer the full range of women's health services [7]. Users of VA healthcare services were younger, more often male, less educated, more often divorced, and more often smokers during the 15 years before death. The leading causes of death in the overall study population were typical for individuals who died in their seventies.

The major finding of this study was that both female and male users of VA healthcare services were more likely to die from alcohol- and/or drug-related causes than veterans who did not use VA healthcare. Most VAMCs offer a full range of substance-use disorder treatment services, which indicates that veterans may be more likely to use these services than publicly funded addiction treatment services that may be unavailable because of limited capacity. Also, many veterans may not have had adequate health insurance or other resources to obtain private addiction treatment. Hence, the VA may be a last resort for veterans needing addiction treatment or other medical care for addiction-related conditions. This finding, along with the younger age at death of veteran VA healthcare users, supports the contention that the VA has a socially disadvantaged and less healthy population [6]. 
Considerable attention has been given to the accuracy of VA death records as compared with state (e.g., Washington State, California) death records or the National Death Index [8-10]. However, very little is known about causes of death in veterans, except for select groups such as Vietnam veterans or veterans with mental illness [1-4]. This article is among the first to describe causes of death in a large unselected group of veterans. The finding of increased mortality related to alcohol and/or drug use likely applies to veterans outside Washington State.

Limitations related to the completeness and accuracy of the underlying cause of death recorded on the death certificate have long been recognized [11]. However, agreement between veteran status recorded on the death certificate and a questionnaire from the 1986 National Mortality Followback Survey was 97 percent [12]. The value of the smoking variable on the death certificate in Washington State has been evaluated as well [13]. Importantly, the data we presented were based on proportional mortality; thus, greater impact on death of a particular cause may not necessarily reflect more frequent or severe occurrence of this cause in a population but rather the less frequent occurrence of other causes. Nevertheless, results from this study suggest that cause of death may provide important information about users of VA healthcare services.

Unfortunately, very few states make their death records publicly available at a reasonable cost for researchers. The National Death Index is also available for researchers but may be cost-prohibitive for studies of large numbers of cases, such as the millions of veterans who have died in the past 10 years. Given that underlying cause of death is of interest not only to researchers but also to policy makers and planners, further efforts to costeffectively obtain this information from the National Death Index should be explored.

\section{CONCLUSIONS}

In summary, mortality related to substance-use disorder occurred more frequently among Washington State veterans who used VA healthcare resources. The reasons for these findings deserve further investigation and may reflect in part more generous VA coverage for addiction treatment in comparison with non-VA health plans.

\section{ACKNOWLEDGMENTS}

This material was based on work supported by the VA Epidemiologic Research and Information Center (grant EPC-010).

The views expressed in this article are those of the authors and do not necessarily represent the views of the VA.

The authors have declared that no competing interests exist.

\section{REFERENCES}

1. Watanabe KK, Kang HK. Mortality patterns among Vietnam veterans: A 24-year retrospective analysis. J Occup Environ Med. 1996;38(3):272-78. [PMID: 8882099]

2. Price RK, Risk NK, Murray KS, Virgo KS, Spitznagel EL. Twenty-five year mortality of US servicemen deployed in Vietnam: Predictive utility of early drug use. Drug Alcohol Depend. 2001;64(3):309-18. [PMID: 11672945]

3. Kang HK, Bullman TA. Mortality among US veterans of the Persian Gulf war. N Engl J Med. 1996;335(20):1498-1504. [PMID: 8890102]

4. Thompson R, Katz IR, Kane VR, Sayers SL. Cause of death in veterans receiving general medical and mental health care. J Nerv Ment Dis. 2002;190(11):789-92. [PMID: 12436023]

5. Dembling BP, Chen DT, Vachon L. Life expectancy and causes of death in a population treated for serious mental illness. Psychiatr Serv. 1999;50(8):1036-42. [PMID: 10445651]

6. Agha Z, Lofgren RP, VanRuiswyk JV, Layde PM. Are patients at Veterans Affairs medical centers sicker? A comparative analysis of health status and medical resource use. Arch Intern Med. 2000;160(21):3252-57. [PMID: 11088086]

7. Maynard C, Kivlahan DR, Sloan KL, Krupski A, Saxon AJ, Stark K. Use of Veterans Affairs health care services by veterans receiving addiction treatment in Washington State. Psychol Serv. 2004;1(2):120-25.

8. Dominitz JA, Maynard C, Boyko EJ. Assessment of vital status in Department of Veterans Affairs national databases. Comparison with state death certificates. Ann Epidemiol. 2001;11(5):286-291. [PMID: 11399441]

9. Cowper DC, Kubal JD, Maynard C, Hynes DM. A primer and comparative review of major US mortality databases. Ann Epidemiol. 2002;12(7):462-68. [PMID: 12377423]

10. Lorenz KA, Asch SM, Yano EM, Wang M, Rubenstein LV. Comparing strategies for United States veterans' mortality ascertainment. Popul Health Metr. 2005;3(1):2. [PMID: 15730553] 
11. Hoyert DL, Lima AR. Querying of death certificates in the United States. Public Health Rep. 2005;120(3):288-93. [PMID: 16134570]

12. Poe GS, Powell-Griner E, McLaughlin JK, Placek PJ, Thompson GB, Robinson K. Comparability of the death certificate and the 1986 National Mortality Followback Survey. Vital Health Stat 2. 1993;(118):1-53. [PMID: 8303839]
13. Frost F, Tollestrup K, Starzyk P. History of smoking from the Washington State death certificate. Am J Prev Med. 1994; 10(6):335-39. [PMID: 7880552]

Submitted for publication January 13, 2006. Accepted in revised form April 7, 2006. 